writing, drawing, music, \&c.),--I find, out of a total of 164 male patients, a residuum of not more than 20 who can be truthfully denominated as hopelessly idle. These are either incurably indolent, or else so demented or intractable as to baffle all efforts to improve them.

Taking into account the comparatively large number of patienta, the classes of society from which they are drawn, the various difficulties in the way of enforcing such a plan of treatment, amongst which the ill-ajvised opposition of relatives and friends is one of the most practical and embarrassing, the result which $I$ have endeavoured to indicate sbove is not, I venture to think, wholly unsatisfactory.

I am, Sirs, faithfully yours,

Liord Francis, M.A., M D. Oxon., Senior Assistant Medical Officer.

St. Andrew's Hospital, Northampton, Aug. 23rd, 1887.

\section{"DIPHTHERIA IN MAN AND THE LOWER ANIMALS."}

To the Editors of THE LANCET.

SIRS,--In a leading article on the above subject in your issue of the 13th inst., you draw attention to a report lately issued by Dr. Turner, in which he deals with the relationship that, according to him, exists between diphtheria of man, the horse, the cow, the pig, and poultry, I have not at present seen Dr. Turner's report, but I am, nevertheless, bound to accept the statement in your article as in some sense reflecting the general conclusions with which it deals.

Dr. Turner seems to have arrived at the conclusion that the disease so well known to veterinary surgeons as affecting poultry, and in which a talse membrane is formed in the mouth, throat, nostrils, and conjunctivæ, is identical with diphtheria, and he speaks of the membranous product as boing found in the trachea. At first sight does this statement bear out the relationship? I have always understood that diphiheria is, in the human subject, mainly localised in the pharynx and fauces, and if $I$ am wrong in this ingrained supposition, I may still fall back upon my experience, and say that I have never yet seen anything approaching a diphtheritic product in the trachea of any feathered creature; but I will not beg the question thus, as I am perfectly well aware that circumstances alter cases, and thatslight histological differences exercise a material influence in the characters of pathological or, more strictly speaking, histological processes. I cannot at the moment remember the name of the pathologist who some time ago stated that the difference between catarrbal, croupous, and diphtheritic products was merely histological, and was dependent upon the difference in the arrangement of the epithelium in the mucou. membrane of the pharanx, larynx, and trachea respectively, and that the same disturbing influence (only in a different degree) that would produce catarrh or croup in one would produce diphtheria in another; and until this statement was published I was at a loss some what to account to my pupils for a fact which I had on more than one occasion observedviz., the occurrence of true diphtheritic products in the larynx and trachea of the cow. Diphtheria I have only seen once in the horse; it is more common in the pig; and a few years ago cases occurred in swine and cattle in the practice of $\mathrm{Mr}$. Campbell, F.R.C.V.S., Kirkcudbright, on farms where diphtheria had prior existence in the attendants. Such statements as that made by Dr. Turner to the effect that "strangles in the horse appears to bave some real kinship with human diphtheria "are gratuitous assumptions, and not borne out by the experience of every-day practice. That strangles in some seasons takes on protean characters is a fact well known to all observant veterinary practitioners that it bears in its essential characters any resemblance to, or has any clinical kinship with, diphtheria are, again, gratuitous assumptions, and all the more so seeing that Dr. Turner attempted to impart to them an air of plausibility by the further statement that "a large proportion of fatal atacks of diphtheria has also been observed to occur in the families of persons-such as shepherds [this brings in the innocent sheep], grooms, and blacksmithswho have to do with the lower animals." Really this is drawing conclusions (if I may be permitted to say s9) from false data with a vengeance. Why does he not wat cowherds and swineherds in the list? Dr. Turner, it seems to me, has lost sight of a well-known law bearing upon enzootics and endemics and epizootics and epidemics, to the effect that in certain seasons this class of affections rage simultaneously, and that the same forces which favour the production or prevalence of epidemics and endemics are equally operative in the propagation and spread of epizootic and enzootic diseases. Returning to Dr. Turner's primary argument as to the prevalence of diphtheria in poultry and pigeons, I may be forgiven when I express the doubt that he has not made himself acquainted with the current medical and veterinary literature on the subject during the past few years, both in this country and on the Continent.

About the year 1865, I saw, in the neighbourhood of Live:pool, cases in poultry which I looked upon as of the nature of diphtheritic aphtha. On my removal to Edinburish (n the years 1871-2), I came across similar cases in pigeone, poultry, and canaries, and in the first lectures it was my privilege to give in the Royal Veterinary College on the subject of infectious and contagious diseases I described an affection that I considered partook partly of the nature of aphtha and partly of that of diphtheria by the dual term diphtheritic aphtha, and which was most certainly contagious and infectious between poultry and pigeons. I further attributed it to the action of a fungus (a leptothrix), and thought that its. production was favoured by insanitary conditions and all influences that tended to lower the vital forces, such as damp. cold, and in-breeding. Some time after this a disease was described by Dr. Fleming, in his "Sanitary Science and Police," under the head of "Gregarinosis" or "Psorospermiosis" the clinical characters of which resembled those of diphtheritic aphtha. The terms mentioned were, if I mistake not, of continental origin, and were applied to the disease because it was believed to be due to a form of psorosperm or gregarina.

In $1879 \mathrm{M}$. Megnin described diphtheria of poultry, and distinguished two forms - (1) a false menbranous form and (2) a tuberculous form, the former being localised in the pharynx, nose, \&c., the latter in the internal organs. and muscles; and Megnin identified the disease (histologically) with the hepatic tuberculosis of rabbits. Megnin also. asserted that M. Nicati sought to identify the affection with the diphtheria of man; but he himself combated Nicati's. identification by drawing attention to the fact that he had frequently seen women and children eat infected poultry with impunity, and by the experiments of Trasbot of Alfort who inoculated pigs and dogs ineffectually, fowls successfully, and who stated that a pupil of his-M. Faies-placed diphtheritic membrane (from fowls) in his own throat with impunity.

In May, 1882, I read a paper on "Specificity in Disease" at a meeting of the North of England V. M. Association held at Newcastle, and amongst other subjects touched upon the disease designated "gregarinosis." For some time I had had doubts as to the nature of the disease, and strongly suspected that causally - as most certainly pathologically -it was intimately related to tuberculosis; but there were certain differences in the characters of its local manifestation which I could not reconcile with those of the last-mentioned disease. These were principally the presence of flattened yellow bodies in the intermuscular connective tissue, the peculiar croupous transformations so frequently seen in the lungs, and the cylindrical croupous and hæmorrbagic masses sometimes forming in and occluding the intestines, with the absence of that marked tendency to calcification so characteristic of tubercular granulomata. In the paper alluded to I concluded my remarks as follows :- "The dissemination of the nodules internally is certainly similar to that of ordinary tubercle, and, as in that disease, death is largely produced by anæmia and exhaustion. But, in otber respects, the two diseases differ widely, though on $\theta$ is undoubtedly quite as specific in its nature as the other."

Since the above-mentioned date I have arrived at the conclusion that the disease might be due to a cladothrix form of fungus, the visible products of whose action were, as in the case of actinomycosis, granulomata. In August, 1883, attention was directed to the subject of Tuberculosis in Fowls, in a leading article in THE LANCET. And again in October, 1884, the statement of Emmerich to the effect that he had discovered a bacterium in the false diphtheritic membrane from pigeons is noticed in THE LANCET. The spread of disease amongst domestic poultry has been going rapidly on for some years, and in several-in fact, I may say in allspecimens examined by the newer methods of staining, my colleague, Professor McFadyean, has succeeded in detecting bacilli identical with those of tubercle. Whether, however, there are two distinct forms of disease in poultry, 
a diphtheritic and a tuberculous, or one disease manifested in different ways clinically, must be left an open question; but of the widespread prevalence of tuberculosis in the feathered tribe there can be now little doubt. An admirable article on this subject appeared in the American Journal of Comparative Medicine and Surgery for October, 1886, by Dr. Bland Sutton ; it was entitled "Avian Tuberculosis."

Edinburgh, August, 1887 .

$$
\text { I am, Sirs, your obədient servant, }
$$
Thomas WaLLEY.

THE ALLEGED CASE OF ASIATIC CHOLERA AT NEWTON-POPPLEFORD.

To the Editors of THE LANCET.

SrRs,--You will probably think the following case of sufficient importance for insertion in an early issue of your valuable journal.

At 7 A.M. on Saturday the 23 rd ult., I was called on to visit John $\mathrm{F}$ - - , aged sixty-seven, a small farmer residing at Newton-Poppleford in the parish of Aylesbeare, distant about nine miles from Exeter. I was well acquainted with the man, who was strong, and enjoyed uninterrupted good health. Formerly he had been rather intemperate, but of late years had been what would be called a "moderate drinker." On my arrival at 9.30 A.M., I was informed that, after a light supper of bread and cheose and a single glass of ale, he retired to rest at 9.30 (his usual hour) on the previous evening, apparently perfectly well. At 1.30 A.M. on Sunday (eight hours before my arrival) he was seized with sickness, which was speedily followed by copious relaxation of the bowels, and in about an hour cramp in the upper and lower extremities set in, and increased with the purging and vomiting until my arrival. No stools or vomicæ bad been preserved. The former were described as "at first iike dirty water and then light yellow," and the vomited matter as "thick and brown," except when he took tea or milk, which was ejected as soon as swallowed. I found him prostrate and restless; features pinched; eyes sunk; the whole surface of his body bore a marked leaden hue, covered with a cold, clammy sweat. His voice (which I heard, and which forcibly struck me as I ascended the stairs to his room) was completely changed into a whine or loud whisper. His respiration was difficult, and the breath and tongue quite cold. The toes and fingers-the skin of which was much pinched-were severely contracted during the cramps, and the muscles of the calf "quivered" during the absence of cramp. He complained of no griping in the bowels, but of great uneasiness at the epigastrium, severe thirst, and craving for cold water, which was allowed ad libitum, but instantly thrown up. Pulse small, thready, and rapid. Temperature in the mouth (taken with great difficulty, and not to be relied on) $98^{\circ}$. At 10.30 P.M. I again visited him, in company with my son (Mr. Bingley G. Pullin). The colour of the body was very livid, the eyes more sunk, the face more pinched, and the hands sodden, as if long immersed in water. Pulse not perceptible. Body covered with sweat of icy coldness. There was at this time a slight return of heat in the breath and tongue, and the purging and sickness had been less severe with the medicine, and he had dozed for a few minutes at a time, but he was now very prostrate and restless, rolling from side to side with sovere cramps. Three stools had been reserved, which closely resembled thin gruel or rice-water. The patient stated that no urine had passed during the attack, but about one ounce was taken, which in his struggles was spilt and the opportunity to analyse lost. My son remained to ensure the necessary remedies being carried out. All, however, was of no use, and the patient succumbed at 2.30 A.M. on Sunday (twenty-five hours from commencement of attack). It was not until an hour before he died that stupor set in and his mind gave way. The contraction of the muscles of the calf continued for two hours after death, and during this period the temperature of the body had risen, but in three hours rigor mortis had powerfully set in. The treatment consisted in the first instance of three grains of calomel placed on the tongue, with ten minims of dilute sulphuric acid and ten minims of tincture of opium, every hour, and subsequently diffusible stimulants of ammonia and ether, with friction and chloroform liniment.

The dwelling was isolated and elevated, and both it and its surroundings were sanitarily satisfactory and the water pure. No diarrhœa prevailed in the family or village, and none has appeared since. It will be asked, What was the cause of the attack? Was it the result of a "specific poison"? I leave wiser heads to determine this point. There was no premonitory stage. It manifested itself suddenly in a most virulent manner, and, as is usual, as far as my experience goes, such cases invariably prore fatal. That the intensity of the attack was determined by the heat of the day, I feel no doubt. During his work on the previous day he came into his house three times to shelter himself from the effects of the sun-quite an exceptional circumstance; and the temperature taken in the neighbourhood that day by one of the most reliable meteorologists (Dr. Radford) was $139^{\circ}$ in the sun-a heat never registered higher in the neighbourhood before, and only once so high. I consider it to have been a case of Asiatic or malignant cholera, and to guide me in this opinion I have the advantage of the experience of the severe cholera epidemic of 1849 , when I acted professionally under the then Government General Board of Health at Portsmouth, Plymouth, and Cornwall. No symptom that I witnessed during that epidemic was wanting in this case. A postmortem examination was refused. I may mention that the coffin was saturated with Burnett's fluid, and the corpse wrapped in cloths saturated with Calvert's strong carbolic acid, and interred in forty-eight hours. The bed, bedding, and everything used during tha illness $I$ insisted on being burnt at once, the house powerfully fumigated, and the entire premises thoroughly cleansed.

I am, Sirs, yours faithfully,

Thos. H. S. Pullin, M.D.

Sidmouth, Aug.23rd, 1837. Medical Officer of Health for Sidmouth.

\section{"PAIN AND ITS INTERPRETATION."}

\section{To the Editors of THE LANCET.}

SIRS,--With your indulgence I would offer a few words in reply to Dr. Collins' letter in your last issue. I am not quite sure how that letter should best be answered, but certainly the worst way would be to imitate its method. No good purpose can be promoted in that way. The burden of this letter is in two remarks. The first is that my statements concerning pain "are so strangely at variance with universal experience and common sense that it is incumbent upon anyone who has read them to controvert them." Now, my answer is that I have the best proof possible that Dr. Collins' knowledge is at fault concerning universal experience, and I fear uncharitable as regards common sense; for I have from utter strangers and from all parts of the country the most unqualifying encouragement to continue my papers on the Interpretation of Disease, and this last paper on Pain has been received most favourably. I have had many private letters concerning it; it has been quoted verbatim by several provincial papers, with very pertinent and encouraging comments; and what I esteemed perhaps more than all this was your own annotation in the same issue, which very distinctly asserted the beneficence of pain.

I trust Dr. Collins will credit me that I am not anxious to entertain any theory of pain that is wrong or unreasonable, but I must say that there is nothing in his letter to convince me that this beneficent view of pain is wrong. The assumption of universal experience and a private property in common sense is scarcely safe, and any ipse dirit based on such disposition is sure to be largely discounted. I must be held excusable, then, if I say I still adhere to every word of my paper. When Dr. Collins charges me with not excepting malignant diseases he does me an injustice. I did make distinct reference to these "apparent exceptions"; no person at all thinking of the matter could escape so doing. But he takes no notice of my attempt to reconcile these with the beneficence of pain. This is unfair and unfortunate; for as long as the philosophy of disease is treated in that manner, so long will our profession rest under an opprobrium medicince worse even than cancer. I have nothing to do at present with the "wider sense" in which pain may be viewed. I am only concerned with the individual, and $l$ am not afraid that anything determined right for the individual shall be found at rariance with the wider signification of pain when that is adequately declared and understood. As to Dr. Collins' own rendering of the matter, which 1 honestly confess I did not understand, the 